\title{
Opinion mining approach to study media-image of energy production. Implications to public acceptance and market deployment
}

\author{
Kalle Nuortimo ${ }^{1)}$, Industrial Engineering and Management, Main author \\ University of Oulu, Finland \\ P.O. Box 4610, FI-90014, Finland \\ e-mail:kalle.nuortimo@shi-g.com
}

Janne Härkönen, Industrial Engineering and Management,

University of Oulu, Finland

P.O. Box 4610, FI-90014, Finland

e-mail:janne.harkonen@oulu.fi

\section{Abstract}

The nature of media image, through either traditional or social media may have an influence on public acceptance of energy technologies. The potential impact on decision-making can make the media image a factor for technology market deployment, similarly as technical, legal and economic factors. The public acceptance has a tendency to be shaped by how technologies are presented in the media. This study compares and analyses the media image of various power production technologies. Editorial and social media is analysed by using M-Adaptive tool for media monitoring to obtain the media sentiment. The analysis is rather covering by including three million social media platforms, and various news outlets in many regions, covering an enormous number of data points from which this study has selected over 250,000 for further analysis with the help of Artificial Intelligence. The results indicate that the public sentiment towards power production technologies varies among different technologies, and between editorial publications and the social media. The editorial content is usually constructed by using news frames, whereas social media includes more emotional content from single users. A potential reasoning from public image to energy technology market deployment is synthesised. The finding support the notion of social media having an increasing role, which may need to be acknowledged to a larger extent. 


\section{Introduction}

The climate change debate has resulted in several energy technologies to cut down $\mathrm{CO}_{2}$ emissions. The renewable power involving for example wind and solar are also seen as options to reduce emissions. These renewable options, however, come with the need to invest in transmission and storage. In addition, baseload technologies such as high efficiency coal power combined with the currently developing Carbon Capture and Storage technology (CCS), nuclear power, and biomass power, all have their potential with different scores on the sustainability criteria and environmental performance. All the prospective climate friendly technology options, however, involve complex techno-economic considerations, while also regulations, policies, and the public acceptance have significance in the market deployment context.

The public opinion about energy technologies is sometimes linked to societal controversies, which might have caused public rejection. Hence, it is important to understand also the psychological determinants of societal acceptance of power production technologies (Gupta et al., 2012). It is necessary to learn from former examples of failed technology commercialisation, particularly the cases that have indicated that the social acceptance has been a decisive factor for the failure. Furthermore, considering the possibilities of early adoption of the public may be an option to ensure technology acceptance (Ashworth et al., 2009). The promotion of the low carbon energy and associated infrastructures that can help in halting climate change is an important task also for governments, worldwide, to gain favourable public opinion. The public opinion and possible local opposition towards certain infrastructures may slow down, or even stop intended developments (Batel et al., 2013).

The scholar's focus on public acceptance of technologies is on the rise if judged by the number of publications (Gupta et al., 2012). For example, the studies by Zoellner et al. (2008) show that there is general support for renewable energy technologies among the public, however, reaching a further increase in renewable energy utilisation would require support for concrete energy systems at a local level. Considering the big picture, empirical studies indicate reasonably high levels of awareness over energy issues and sources. However, controversy exists in terms of rather wide awareness of the "iconic" examples of sources of renewable energy, wind and solar, opposed to the lack of adequate awareness of the potential of familiar low carbon sources or technologies such as biomass and carbon capture (Devine-Wright 2007). For the less familiar technologies, such as the CCS, one main challenge involves the public perception and the unfamiliarity with the technology (Wallquist et al., 2010). Potential media analyses ought to analyse the relation of known and unknown energy technologies to the perception of risk, and the further impact of perceived acceptance on market deployment initiatives. The roles of different types of media should also be clarified to cover the more filtered perspective and that of a more direct nature.

This study approaches energy technologies by the means of learning machine based media analysis. The media analysis mines opinions to clarify the energy production related media image of several technologies. The study focuses on exceptionally large data-set to analyse the media sentiment in both, the editorial and social media. An attempt is made to describe a potential reasoning from public image to energy technology market deployment. The application of Artificial Intelligence based media-analysis is assumed to provide benefits compared to traditional narrow qualitative methods, such as questionnaires and interviews. 


\section{Literature review}

It is not necessarily the technology properties, but also the trust in stakeholders that have influence on the public acceptance of technologies (Terwel et al., 2011). The size of the project and local history may also have influence on local public acceptance, aside the trust in stakeholders (Dütschke, 2011). Trust in organisations surrounding the technologies affects people's perceptions of the magnitude of risk, and the benefits, influencing their acceptance (Terwel et al., 2009). Similar logic has been presented for example for the public acceptance of gene technology (Siegrist, 2000), and for nuclear waste where overwhelming political opposition has been fuelled by the public perceiving risks (Slovic et al., 1991). Education can also affect the public acceptance by increasing public acceptability and thereby reducing fundamental opposition (Itaoka et al., 2004). Lay attitudes are seen relevant, in fact, people's acceptance is seen critical for the widespread deployment any of low-carbon technologies to become a viable options for reducing $\mathrm{CO}_{2}$ emissions (Fleishman et al., 2010). Past examples exist for public acceptance being a major hindrance for cost-effectively developing new energy infrastructure, affecting many technologies, including nuclear (Grove-White et al., 2006), CCS (Bradbury et al., 2009), Wind farms (Firestone and Kempton 2007), Gene technology (Siegrist, 2000), nanotechnology (Siegrist et al, 2007a) and many others. Factors such as radiation fears (Kim et al., 2013), risks to animals (Wolsink, 2007), carbon dioxide release (Wallquist et al., 2010) and other potential consequences (Siegrist et al., 2017b; Zechendorf, 1994;) are seen to affect the public acceptance. For this type of reasongs public acceptance is a challenging consideration for public policy development involving technologies (Itaoka et al., 2004). Merely educating to increase the public awareness over the responsibility to mitigate $\mathrm{CO}_{2}$ emission would not necessarily enhance the acceptability of the energy technologies (Itaoka et al., 2004), but information may raise support for some aspects of the technologies. On the other hand, information may in some cases result in stronger opposition (Palmgren et al. 2004). It is obvious that different and even opposite information exists. Noteworthy is that public acceptance is seen to depend on the information provided by different actors, the people influencing and relying on each other, making gaining trust important (Huijts et al. 2007). Social media for example provides a potential avenue for people to interact among each other, supporting the social process needed for public acceptance. The traditional media's role is more to provide information. International demonstration may also be required to enhance confidence and trust, as widespread deployment necessitates public acceptance (de Coninck et al., 2009). Benefit and risk perceptions are presented as determinants of public acceptance, which is emphasised to have a strong impact on the progress of technologies (Wallquist et al. 2010). Wüstenhagen et al. (2007) present public acceptance along three dimensions of socio-political acceptance, community acceptance, and market acceptance to understand possible contradictions surrounding technology market deployment. Awareness is a key consideration in people's behaviour, also impacting their opinions. Visibility in media creates awareness and instigates knowledge. The public trust can be impacted by the visibility, awareness and knowledge. Hence, possibilities of different technologies may be influenced by public acceptance. It is recognised, that public acceptability is a necessary condition of technology development and diffusion, however raises many questions about the psychological processes shaping public responses (encompassing cognitive perceptions, emotions and behavioural responses) about the ways in which public responses are being conceived and responded to by key stakeholders such as local government, industry and interest groups (Devine Wright 2007). The following proposition is developed:

P1. Trust in stakeholders, technology specific fears, visibility, knowledge and education are factors that affect how risks are perceived, influencing public acceptance, not just the technological aspects. Public acceptance is somewhat unknown factor in technology related policy considerations, but necessary for technology advancement. 
The potential of technologies is easily missed due to the lack of public acceptance. For example, coal power seems to be currently in public opposition due to $\mathrm{CO}_{2}$-emissions and the nature of incentives towards preventing global warming. The studies indicate, that the people who trusted authoritative institutions, such as government, were usually supportive also towards coal technologies. On the other hand, it seems that renewable technologies are not so much liked as coal technologies are disliked (Sovacool, et al., 2012). Technological solutions may exist for addressing the negative aspects of the less accepted technologies. One of the most studied recent R\&D solution has been the Carbon Capture and Storage (CCS) technology that enables capturing the $\mathrm{CO}_{2}$ after the combustion process and storing it permanently. The solution would allow the large-scale energy production. The technology is also suited for future power systems using large shares of low-carbon generators such as renewables that are seen necessary to stop global warming below $2{ }^{\circ} \mathrm{C}$ (Brouwer et al., 2015). Hence, regardless of the negative connotation of coal technologies, the public acceptance is important for the successful market deployment clean coal technologies such as CCS (Huijts et al., 2012). Despite of technological possibilities and the availability of carbon dioxide storage sites, the possibility of $\mathrm{CO}_{2}$ leakage affects the public acceptance. CCS is an example of ongoing long-term media communication activities and the commercialisation being dependent of the public opinion (Ashworth et al., 2009). Media image has influenced the public acceptance, and furthermore, public opposition has influenced CCS projects directly in the form of local action groups, and indirectly via making the political climate unfavourable for CCS (Wallquist et al., 2010). Allowing improved understanding of the possibilities and the applicability of CCS has the potential to improve the trust and confidence on the technology (de Coninck et al., 2009). The main challenge with the public perception is that in most countries the public is rather unfamiliar with the technology (Wallquist et al., 2010). The following proposition is developed:

\section{P2. Technology potential is possible to be missed due to negative connotations causing public opposition and hindering adequate technology demonstrations.}

Also the nuclear power and for example gene technologies to common debates, which can have caused public rejection, highlighting the significance psychological features of technology acceptance (Gupta et al., 2012). The studies indicate, that people's acceptance of nuclear power is influenced by the available alternatives, whereas the previous nuclear accidents have further increased the public opposition towards nuclear power (Siegrist et al 2013). The term "reluctant acceptance" can be used, when comparing people's perception of nuclear power to climate change, thus showing that if people are shown the benefit of nuclear power in mitigating climate change and are asked to choose between nuclear power stations or climate change, they will cautiously prefer nuclear power stations and its waste over the consequences of the climate change (Pidgeon et al., 2008). Also, various studies indicate, that willingness to take action against or in favour of nuclear power stations, is dependent of the perception of nuclear risks, which seems to reduce the public acceptance or its preference for nuclear power (Greenberg, 2009a; Tanaka, 2004). Also people's willingness for opposition is increased alongside the perception of risk (de Groot and Steg, 2010). On the other hand, perceived benefits are seen to increase the acceptance of nuclear power (Tanaka, 2004). The Fukushima Daiichi nuclear power plant accident in Japan that took place in March 11, 2011 has affected the acceptance of nuclear power in various countries (Siegrist et al 2013). Also, based on the research on the accident in Chernobyl, Ukraine, it appears that such accidents may influence the formation of a more negative attitude towards nuclear power (Eiser et al., 1989; Verplanken, 1989). The Fukushima accident had a clearly negative impact on the acceptance of nuclear power, however, the mean change was considered moderate, and was strongly influenced by participants' preFukushima attitudes (Siegrist et al 2013). Nevertheless, many discursive strategies can be used in communication concerning nuclear power technologies, depending on the country, including approaches of necessisation, naturalisation, scientification and rationalisation (Teräväinen et al., 2011). The following proposition is developed: 
P3. Available alternatives may influence the public acceptance, as well as can the acceptance be reluctant when having to select among options. The perceived benefits and risks also have a role.

Renewables such as wind power are implicated strong overall public support according to surveys, while concrete projects are suffering from the "not in my backyard" (NIMBY) syndrome (Wolsink, 2000). For example, UK's Sustainable Development Commission describes the following; "Wind power development arouses strong opinions. For the general public, a high level of support nationally for wind power can be contrasted with opposition at the local level." (Barry et al., 2008). Studies by $\mathrm{Ek}$, (2005) indicate, that the public opinion is generally positive towards wind power; however, the probability of finding an average individual in support of wind power seems to decrease with age and income. The study by Ladenburg, (2008) showed results, that younger people are more positive towards wind power than the older generations. Key assumptions towards wind power include such as that the majority of the public supports wind power, and opposition to wind power is therefore considered deviant. Opponents are ignorant or misinformed, hence the reason for understanding opposition is to overcome it and trust is seen as the key (Aitken, 2009). One feature towards single projects is the labelling the opposition, 'NIMBY' being the best-known label, without examining the reasons underlying the opposition (Firestone et al., 2012). Ladenburg, (2008) has studied Danish windmills, with an indication, that people living close to wind turbines seemed not to display more negative attitudes when comparing to those not living close to turbines, while in general Danish population has positive attitudes, which seems to correlate with age (negatively), gender, experience with off-shore wind farms and the use of the beach. Kaldellis, (2005) indicated acceptance towards existing Greek wind parks and resistance towards new ones. The divergence in local project support has been found to be most stark when only those who to live in very close proximity to the project were considered (Aitken, 2010). Warren et al. (2009) highlights how, whilst some of the controversy centres on factual issues, such as job creation, intermittency or bird mortality, the primary reasons why consensus is not reached, are related to conflicting values, such as aesthetics, community (dis)empowerment, and those that can be perceptual, unquantifiable and shaped by personal world views. In Australia, four common themes influencing the societal acceptance have been discovered, namely trust, distributional justice, procedural justice and place attachment (Hall et al., 2013). The researchers and policy makers have been led to the impression that public acceptance for renewable power should not be an issue by the overall positive attitude. They fail to realise that the acceptance is not static but is subject to changes (Heras-Saizarbitoria et al., 2011). The following proposition is developed:

\section{P4. Positive general acceptance of energy technology does not alone guarantee local acceptance, nor is the acceptance situation static.}

The renewable energy has related to positive attitudes, positive particularly towards biomass power, however, the source may have significance as, for example, attitudes are slightly less positive towards forest-based bio-energy (Qu et al., 2011). According to Halder et al. (2011), positive attitude towards learning about bioenergy does not always fully correlate with the attitude towards it as was revealed by a study on ninth grade students and their attitudes towards bioenergy. There are indication that renewable energies are supported in general among the public. Expanding renewable energy utilisation, however, would necessitate better support for energy systems locally (Zoellner et al., 2008). Factors such as knowledge, household income, and assumptions of the renewable energy cost have a tendency to influence attitudes (Liu \& Zhang, 2013). Risk perception is seen to link policies and public attitudes, majorly affecting the public sentiment and policy related conditions (McGuire, 2015). The following proposition is developed: 
P5. Attitudes and support towards energy technologies can be different in respect to willingness to learn about, and willingness to utilise the technology, and are affected by many socio-economic factors.

Attitudes are conceptually different from acceptance, and there exists a whole branch of attitude study in marketing research. Attitudes are an essential research topic in advertising/marketing studies for mainly two reasons, they can be used in predicting consumer behaviour (Mitchell and Olson 1981), and there exists several theoretical frameworks for the study of attitudes from social psychology researchers (Eagly and Chaiken 1993), thus influencing the research on this topic. Mitchell and Olson (1981) define attitude toward the brand as an "individual's internal evaluation." This is a useful definition, while it incorporates two characteristics of attitude that have remained stable across 20thcentury definitions (Giner-Sorolla 1999) 1) Attitude is centered at an object and 2) attitude is evaluative, so there is "imputation of some degree of goodness or badness" to the attitudinal object (Eagly and Chaiken 1993). Mitchell and Olson (1981) define that internal evaluation is noteworthy, thus it describes the attitude as an internal state, and following Eagly and Chaiken (1973), Spears and Singh (2004) add that an attitude is an enduring state "that endures for at least a short period of time and presumably energises and directs behaviour."

Market deployment, on the other hand, suggests the degree of action directed toward managing organisational resources in the marketplace (Slotegraaf et al., 2003). Market deployment follows the R\&D activities in the product cycle (Midttun and Gautesen, 2007), but is influenced by various factors, including technological, political, financial, and such, that can promote or hinder the market deployment. Money is an important factor causing market deployment of new energy industry solutions to necessitate private finance (Mathews et al., 2010). Stakeholders also have an influence on the market deployment (Lund, 2007). Public acceptance provides some insight over the reactions of general public towards power technologies and projects, with possible influence on market deployment. The following proposition is developed:

P6. Market deployment of energy technologies is affected by various factors, the general public being one of the stakeholders.

\section{Research method: learning machine based media-analysis utilising big data}

The research methodology involves using learning machine based media-analysis that covers a vast number of social media and editorial sources. The founding principles are applied in various previous studies. For example, media analysis has been before to reveal the public acceptance, but with much smaller datasets. Also, sentiment analysis has been applied before, for example in marketing research. Hence, this study utilises the existing methods and extends the analysis to cover also the social media aside the more traditional news media. This as the social media has increased its significance as a data provider, making it an excellent platform for analysing public attitudes (Penalver-Martinez et al., 2014). By utilising a learning machine, the quantity of analysed media sources is increased significantly compared to traditional questionnaires and interviews, or other means of media-analysis. Merely relying on traditional qualitative methods would not allow a significant global media coverage, and responses would be difficult to code, while answers might vary by participants with a risk of receiving socially desired responses (Sovacool et al, 2012). Hence, the research setting of this study is a modern media-analysis with a large dataset. The data is studied to provide perspectives to the interface of public acceptance, political decision-making, and the possible links to technology market deployment. 
Opinion mining can be seen to be highly active field consisting of natural language processing, computational linguistics and text analysis technologies with a target to get various added-value and informational elements from users opinions (Penalver-Martinez et al., 2014). This study is based on a commercial software as the dramatic increase in number of online sources, including discussion forums, blogs and many other forms has necessitated developing computer assited tools for clarifying attitudes and preferences (Neviaroyskaya et al., 2014). The role of media is highlighted as individuals and organisations are increasingly adopting public opinions through different forms of media when making their own decisions (Liu et al., 2012). To utilise public opinions, multiple systems have been constructed in an attempt to quantify the opinions, to review products (Godpole et al., 2007), predict financial markets (Nassirtoussi et al., 2014), and more common marketing and brand follow-ups in the consumer-related manufacturing industry (Abrahams et al., 2013).

This study carries out learning machine-based analysis by utilising commercial M-Adaptive software. The motivation for selecting the current software was the applicability for the analysis. This even if the search algorithms are not publicly available due to intellectual property rights. The same analysis would be possible by the means of content analysis, but would require dealing with such an amount of data that it would be practically impossible to realise. Questionnaires and interviews would also provide more limited information. The main benefit compared to open access software is the inclusion of payable editorial sources that widen the variety of sources. The scale of analysed sources vary from local discussion forums to major influential newspapers, including both structured and unstructured data sources. Particularly including social media sources provides additional insights to public opinion/acceptance, opposed to traditional studies that are exclusively based on editorial media framing. The methodology selection is illustrated in Figure 1.

Methodology selection basis

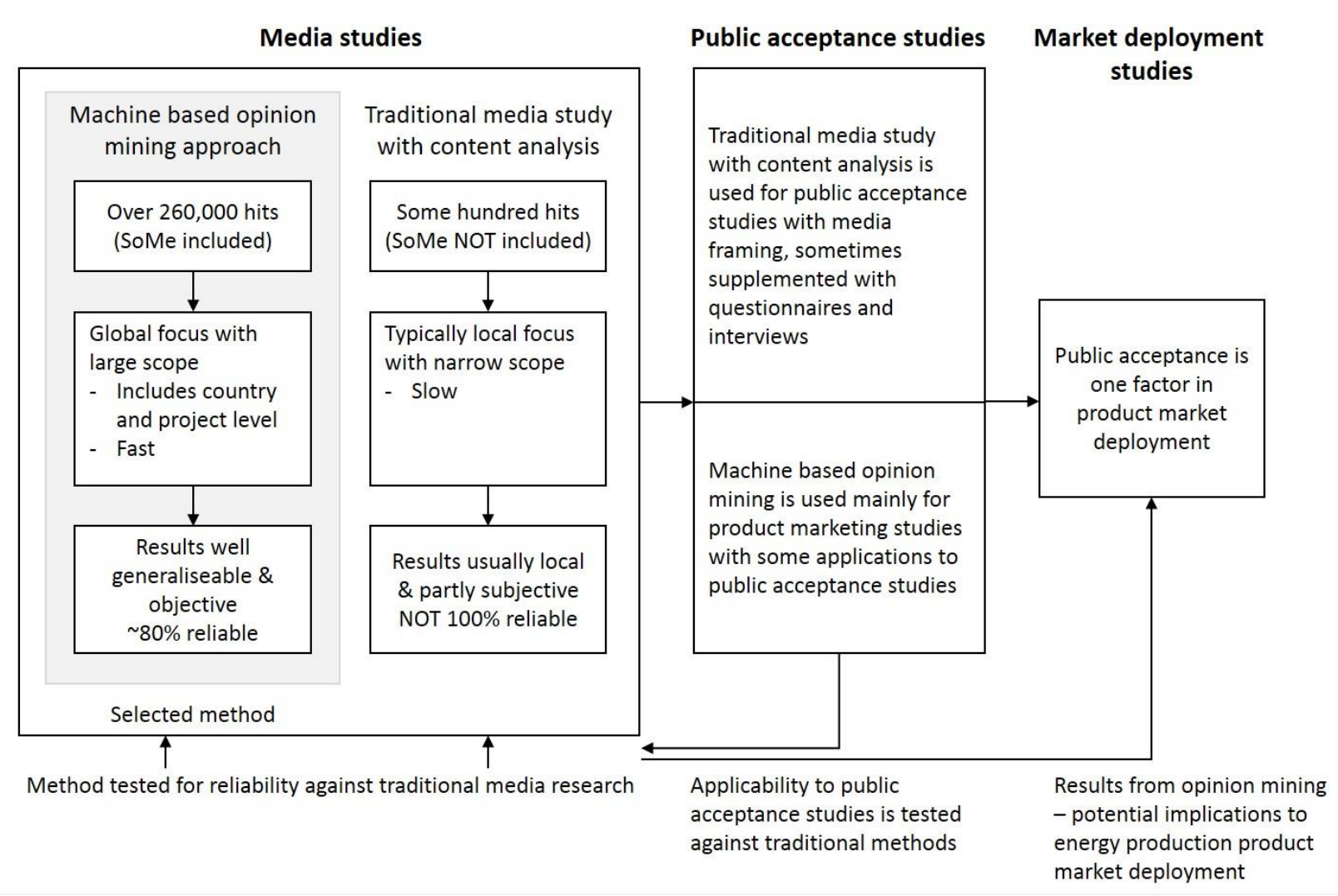

Figure 1: Methodology selection 
The methodology is linked to computational linguistics, where the sentiment is defined by automatic algorithms based on a large dataset. Sentiment analysis is one of the most important applications in the field of text mining. It computes people's opinions, comments, posts, reviews, evaluations, and emotions which are expressed on products, sales, services, individuals, organisations, etc. (Kumar $e t$ $a l ., 2017)$. This concept also includes a whole research area with its own theoretical base. This study applies the method on big data to mine and analyse the opinions relating to energy technologies Big data instigates new challenges for data processing, storage, representation, pattern mining and visualisation in the fields related to natural language processing, data mining, text mining, machine learning, social networks, and sentiment analysis (Bello-Orgaz et al., 2016). The unstructured data in social networking, blogs, reviews, posts, comments, and tweets, are rapidly growing in quantity, and can be seen as an important source for sentiment analysis (Zhang et al., 2008). Sentiment classification aims to mine the written documents (comments, posts, reviews, tweets, etc.) about the topic under interest and classifies the content into positive or negative (Ye et al., 2014). In this study, the classification is made by algorithm developed by the software provider, and the result are presented for whole documents with a classification of positive, negative, neutral, mixed, or unknown. These sentiments are manually grouped in excel software, based on volumes. Editorial and social media are handled separately to highlight the differences.

Search words were used to reveal the relevant discussion. The selected search words include: nuclear power, biomass power plant, coal power, Carbon Capture and Storage (CCS), solar power, and wind power. The analysed sources cover 3 million social media platforms, 100,000 news outlets in 71 languages in 236 regions. (M-Brain). The sentiment analysis applied in this study is based on a combination of linguistic knowledge and human aided machine learning, which means that the software makes suggestions of classifications to humans, and humans then provide feedback on the correctness. This procedure helps the system learn to improve its classification of content into sentiment categories. The analysis was carried out for the period of one year 2.7.2015-3.7.2016. The analysis period is limited by the available computational power. As for any artificial system, humour, sarcasm and irony are also beyond the system's abilities to understand. Table 4 compares the automated methods to human based media-analysis.

Table 4. Comparison between human based and machine based media-analysis

\begin{tabular}{|l|l|l|}
\hline & Human based & Machine based \\
\hline Quantity of data-sources analysed & Small & Very large \\
\hline Subjectivity & Subjective & $\begin{array}{l}\text { Objective (machine makes the same mistakes } \\
\text { always at the same way) }\end{array}$ \\
\hline $\begin{array}{l}\text { Accuracy in sentiment } \\
\text { classification }\end{array}$ & Less than 100\% & $\begin{array}{l}\text { App. } 80 \% \text { with large sets, depending on } \\
\text { selected software }\end{array}$ \\
\hline $\begin{array}{l}\text { Framing and classification } \\
\text { possible }\end{array}$ & Yes & $\begin{array}{l}\text { Classification possible by type and sentiment, } \\
\text { gender, geography, source, etc. defined by } \\
\text { used method/software }\end{array}$ \\
\hline
\end{tabular}

\section{Comparing media image of power technologies}

The public acceptance can be seen to be implied by the media image/sentiment that can be analysed through the data points. The large number of data points can provide a lucrative setting for the analysis. The machine-based analysis revealed a large amount of data points $(264,076)$ of which 116,167 were Editorial and 147,909 Social Media (SoMe) based. Especially SoMe provide an unfiltered media sentiment. Figure 1 illustrates the sentiments towards different power technologies as revealed by the social and editorial media. The media sentiments reveal clear differences between 
power production technologies, as well as differences between that in the editorial content and in SoMe.

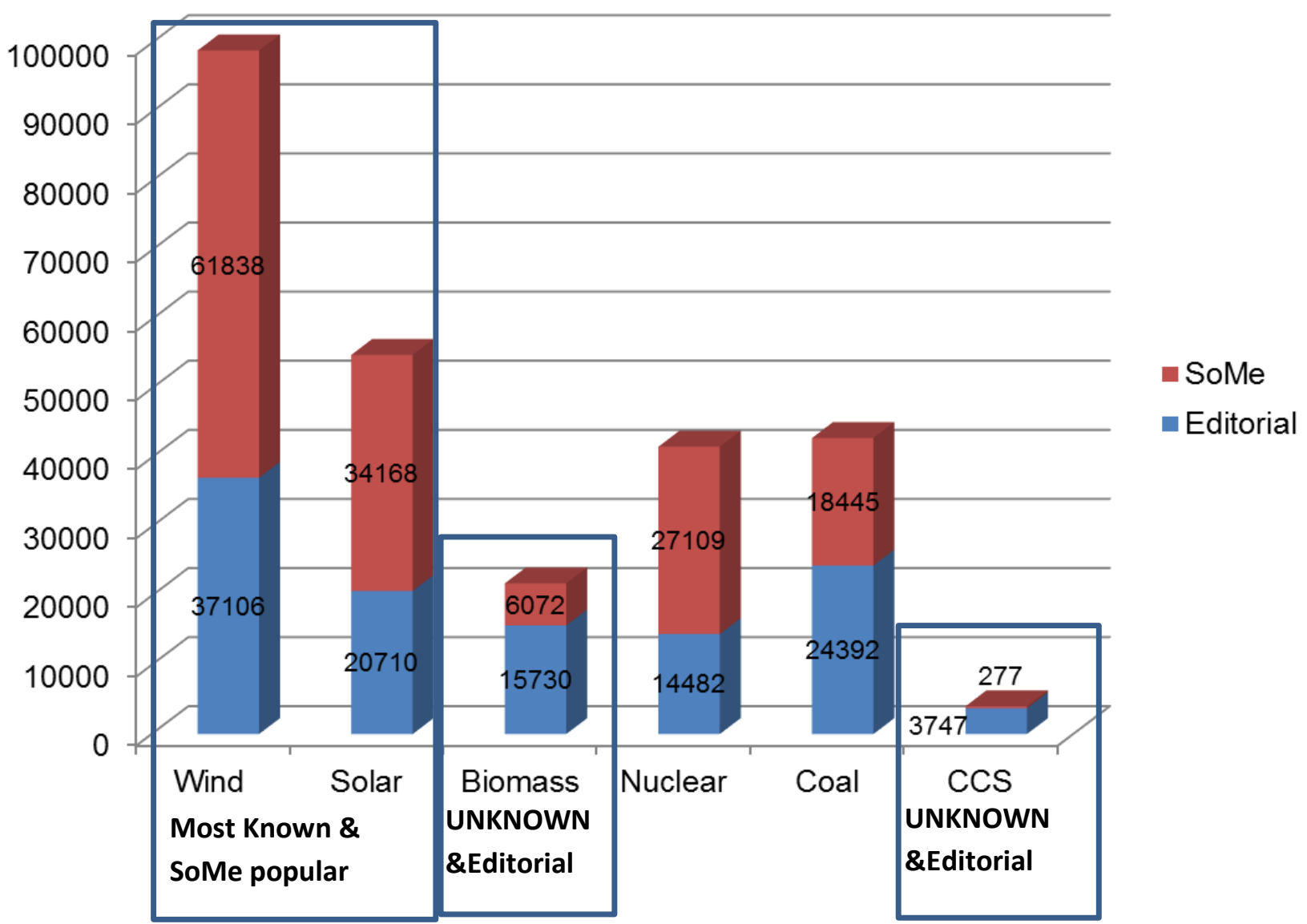

Figure 1: Sentiment analysis of Some vs. editorial publication

Out of the total media attention during the analysed period, wind had gained the most $(98,944)$, and solar the second $(54,878)$ most attention. This was closely followed by Coal $(42,837)$, and nuclear power $(41,591)$. Biomass power $(21,802)$, and CCS $(4024)$ had gained the least attention. The wind power received the most hits in social media $(61,835)$, followed by solar power $(34,168)$, nuclear $(27,109)$, coal $(18,445)$, biomass $(6072)$ and CCS (277). CCS was practically non-existent in the social media. In the editorial media, wind power gained the most hits $(37,106)$, followed by coal $(24,392)$, solar $(20,710)$, biomass $(15,730)$, nuclear $(14,482)$ and CCS $(3747)$. The distribution of media points indicates that communication concerning biomass and CCS is concentrated to editorial media, and between experts. The non-visibility in the social media is a possible indication of the absence of technology popularisation efforts. Higher popular type of communication was evident for low- $\mathrm{CO}_{2}$ emitting power production, the wind, solar and nuclear, for which the media attention in SoMe has been much more intensive.

Finding 1: Learning-machine based media analysis can be used to reveal the media sentiment of different energy technologies, both in the editorial publications and the social media, one that indicates the public acceptance of rejection. 
Figure 2 illustrates the nature of the media sentiment in editorial publications. It can be seen how a large share of hits in editorial publications for wind power, solar power, biomass, and CCS have been positive. For nuclear and coal power the inclination of the hits is negative, possibly indicating a relative low technology acceptance among the journalists.

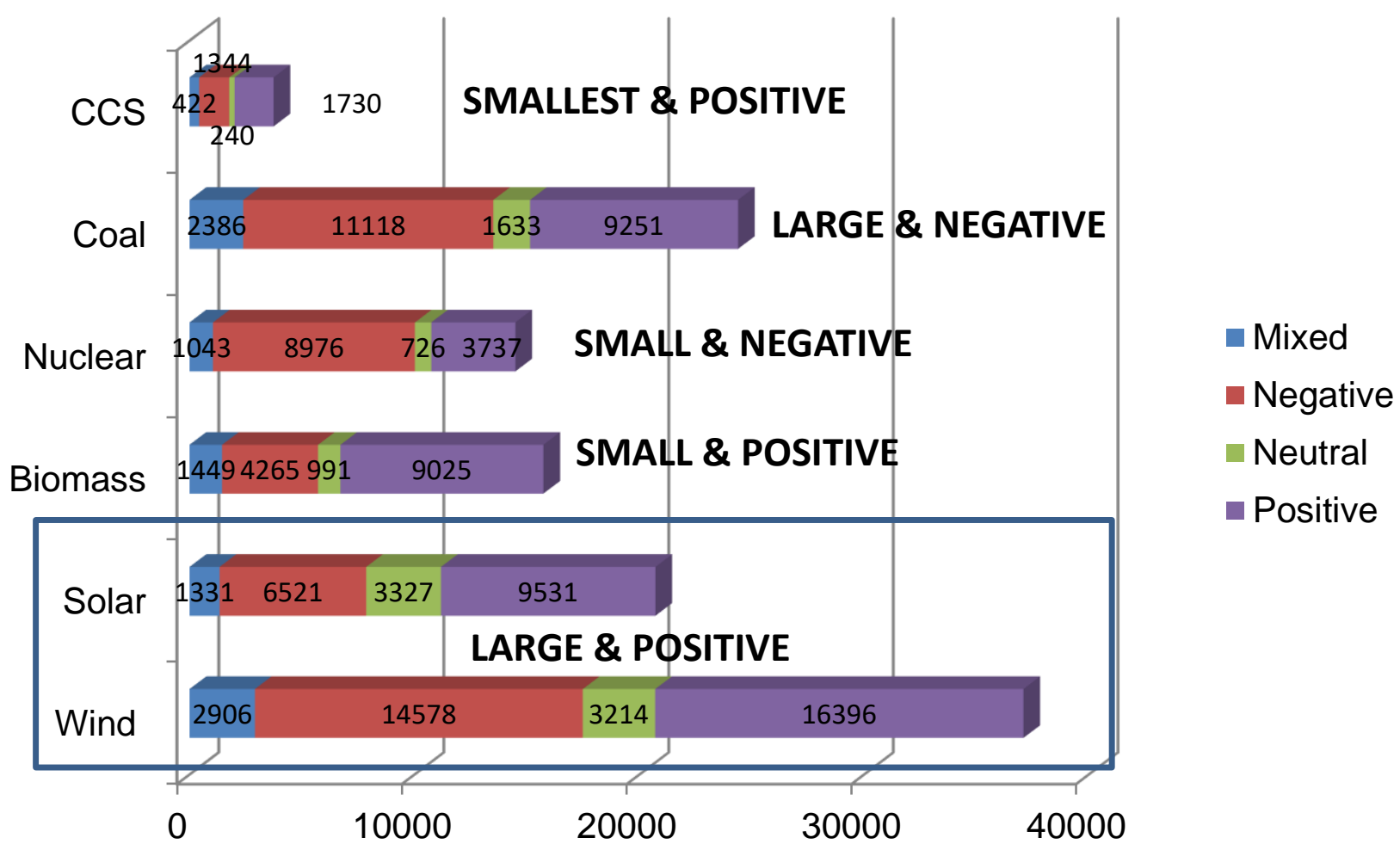

Figure 2: Sentiment analysis of editorial publications

Finding 2: The media sentiment can be used to analyse the technology acceptance of different energy technologies, to compare how the technologies are seen, and to aid in analysing the potential factors influencing the acceptance or rejection.

Figure 3 shows the nature of the media sentiment in social media. It can be seen that public sentiment towards wind power in social media, has been mostly positive. Also solar power is viewed rather positively. The sentiment in social media, however, seem slightly different compared to editorial publications, thus emphasising the importance of analysing SoMe in comparison to traditional news media. 


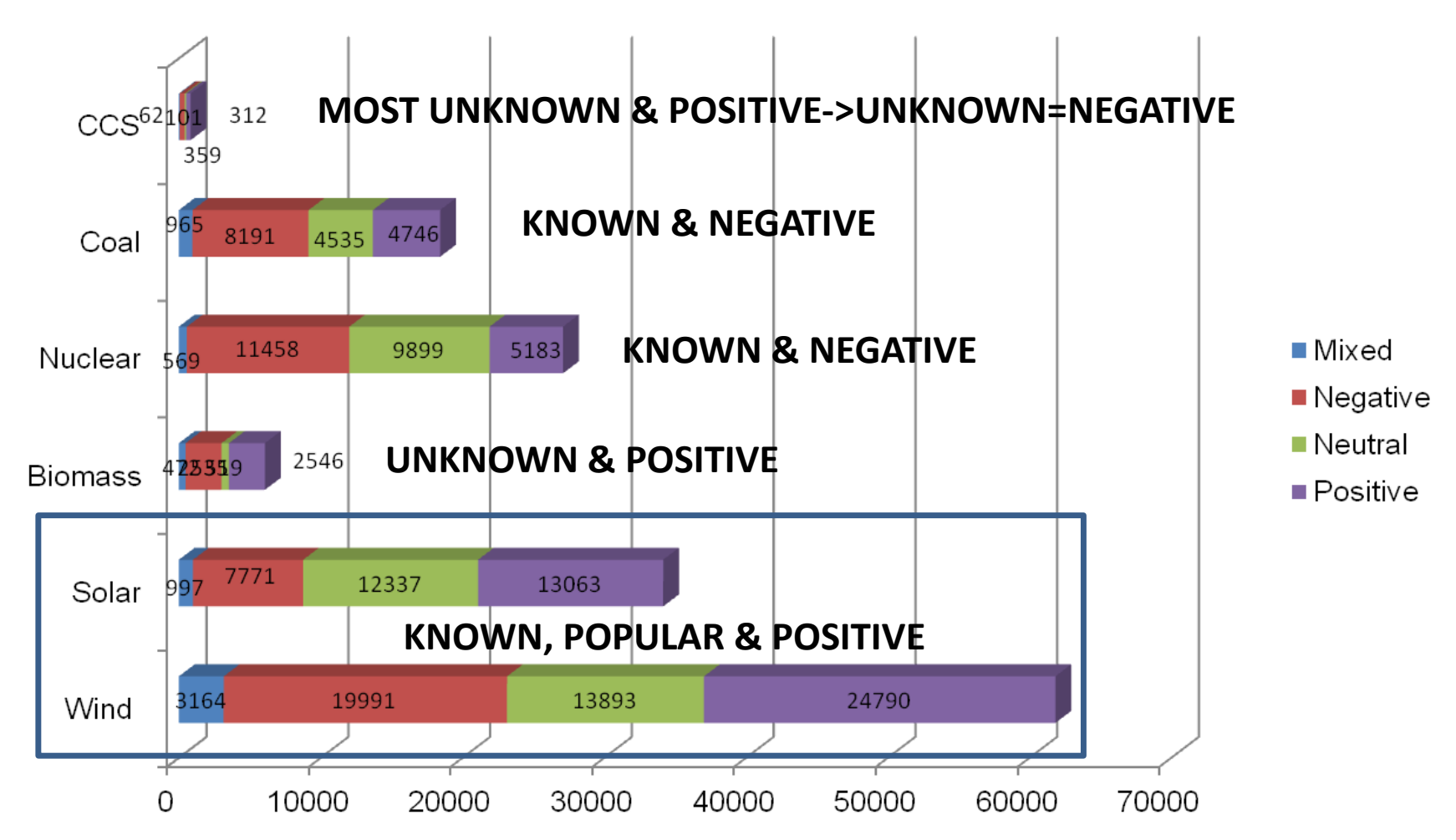

Figure 3: Power production media sentiment in Social Media

Figure 3 shows how public sentiment toward solar and wind have clearly been the most popular and positive, indicating that these technologies are the most known by lay-people. Deeper analysis of different forms of SoMe also revealed that wind power resulted most positive hits also in short popular communication, in twitter. The coal power and nuclear power are well known, but with a clear inclination towards negative general sentiment. Interestingly, in twitter the nuclear power was seen the most negative. Biomass and CCS, on the other hand, are the most unknown technologies to laypeople.

Finding 3: The media sentiment in the social media provides a more unfiltered point of comparison to support that of edited media for analysing public acceptance of energy technologies.

If comparing the media sentiment of different power production it can be seen how the CCS sentiment is more positive and much smaller, compared to coal power that is inclined more towards negative and gains more hits in SoMe. This indicates the negative image of coal power may possibly override the positive smaller exposure of CCS. This due to CCS potentially being associated as coal technology. In contrast to already existing low- $\mathrm{CO}_{2}$ emitting power production, namely wind, solar and nuclear, the media attention in SoMe for those technologies has been much more intensive. There seems to be a clear indication that communication concerning biomass and CCS is concentrated to the editorial media, and between experts, thus being a possible indication of the absence of technology popularisation efforts. In contrast, the media attention in SoMe has been much more intensive on wind, solar, nuclear, and coal, indicating the wider existence of more popular type of communication.

Finding 4: The media analysis reveals that solar and wind power are best known with inclination towards positive public acceptance. Coal and Nuclear power are also both known, but the inclination is towards negative acceptance. Biomass power can be seen to be more unknown, yet with an inclination towards positive acceptance. CCS appears as rather unknown technology with an inclination towards positive image, but being unknown potentially affecting the acceptance. 


\section{Discussion: The chain from media image to product market deployment}

This section attempts to synthesise a link from media image to technology market deployment for the energy production technologies. Applicable communication theories and empirical results from the media-analysis are utilised. The possible effect of media image to product market deployment for various technologies is presented in Figure 4. Causality is not suggested, or any direct effect, merely a link that requires further analysis. This study provides new to the previous discussion in terms of attempting to synthesise a link between media image of energy technologies (an implication of public acceptance), and the market deployment. Public acceptance and media image are discussed in different fields with varying focuses, for example there exists hundreds of communication theories discussing mass media effects (Noelle-Neumann 1973, Karvonen, 1999), branches of research discussing psycho-sociological sides in public acceptance (Huijts et al., 2012, Ladenburg, 2008), NIMBY (Devine-Wright, 2011, Firestone et al., 2012), attitude research in marketing (Mitchell and Olson 1981, Eagly and Chaiken 1993), etc. Figure 4 therefore contains interpretation and should be considered as an initial explanation for the impact of media image on different energy technologies.

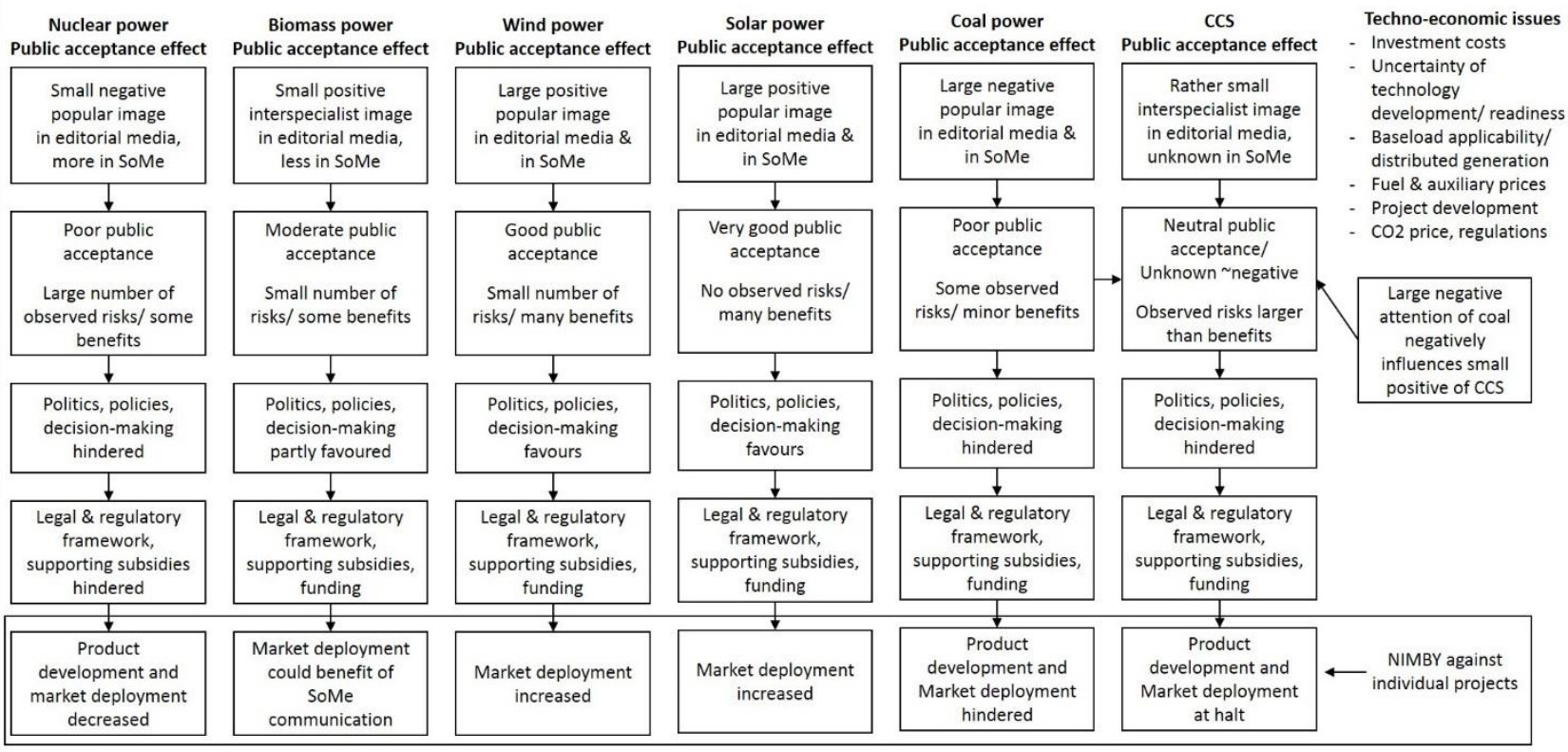

Figure 4. A possible chain from public acceptance and media-image to product market deployment in case of different power production technologies.

Finding 5 The potential reasoning, and related factors, from public image to energy technology market deployment can be described at a level without explaining the detailed logic of the entire chain from public acceptability to the actual effects to managerial decision-making and technology deployment.

The descriptive reasoning chain begins from the public image, which can be seen to influence people's perceptions of technology. This study supports the view that public opinion can be shaped by the news media on any issue through emphasising some elements over others (Shah et al., 2002), whereas Social Media presents more direct opinions, often including emotional content (Stieglitz and Dang-Xua 2013). This study provides new perspectives to the energy technology debate by supporting the notion that the social media can support market intelligence and product development (Berendsen et al., 2015) through understanding the true opinions of the public. On the other hand, in 
line with previous studies, also the energy technology actors can utilise editorial media framing and its potential to influence public acceptance as attention is focused and placed at a field of meaning (Heras-Saizarbitoria, et al., 2011). Following this path, PR-communication literature, uses the rule of effects to describe the chain from media exposure, via attention, comprehension, motivation, and behavioural trial, to sustained behavioural change (McCorkindale et al., 2013). Even though understanding the necessity of extensive media exposure if attempting to influence public acceptance, this study does not take a position on the needed amount of exposure.

The findings support the previous literature noting higher levels of public awareness of energy technologies such as wind and solar, over less familiar low carbon technologies such as biomass and carbon capture (Devine-Wright, 2007). Hence, this study also support findings emphasising how the unfamiliarity by the public is a challenge for public perception in relation to those technologies (Wallquist et al., 2010), and is bound to impact the acceptance. This can be challenge even if the sentiment would be positive as if something is unknown; it is also increasing the perception of risk towards the technology.

Considering development and technology deployment of single company, the political, regulatory and techno-economic factors play a role for both technology development and for market deployment. The public acceptance and the public image of different energy technologies do have an impact on market deployment through a mechanism that can be challenging to reveal fully. However, regardless of the exact mechanism, one crucial question remains, how to quantify/measure the power of public acceptance. The energy technologies could also be discussed in marketing terms, and discuss branding. For example, in a way, solar power can be seen to have a positive brand image, with implications to its technology deployment. On the other hand, the situation is quite the opposite for CCS in terms of the technology being generally unknown with perceived risks, an unknown brand. Simultaneously there is a possibility that CCS will be associated with coal technology that has a negative brand image, and large negative popular type of exposure. There is a likelihood that the negative brand image of coal can hinder the technology deployment efforts for CCS.

The managerial implications of this study include indicating some general power investment related techno-economic and environmental considerations that can be beneficial both for companies considering their development efforts, but also managers in relevant fields. The utilisation of media analysis mining for opinions can be used to indicate public acceptance, information that can be beneficial for project managers to analyse their communication needs. This study also highlights the possibility of companies attempting to influence the public to create more favourable environment for certain energy technologies. Furthermore, for managers planning or involved in power projects, this study highlights the need for public engagement, and addresses the urgency for social media participation. Companies can benefit of the results when considering the role of popular communication. For example, when thinking of resourcing company's PR communication function, social media can be an essential point of focus, especially if nuclear or coal power, or any other energy technology, in the company portfolio.

\section{Conclusions}

It is evident that the public image of different forms of power production varies. The media image of coal and nuclear power appears as clearly negative. Biomass, and CCS, on the other hand, appear as clearly unknown affecting the perception of risk in the public eyes. The public image of wind and solar energy appear as the most positive, while these forms of power production also appear as the 
best known to the public. The visibility of energy technologies in the social media can provide a beneficial point of comparison against the sentiment in the editorial media, aside revealing the unfiltered public opinions.

From the perspective of power technologies, the media image alone, may, however, be an oversimplified consideration as it does not account for factors such as whether something is a baseload technology or not, or whether the particular form of power production requires back-up power or additional energy storage due to fluctuating power production. There is also the question of the end storage of side products in case of nuclear power and CCS, nuclear waste and $\mathrm{CO}_{2}$ that can cause challenges in the public acceptance. Hence, the overall energy system consideration is not accounted for, leaving the possibility that the public opinion might be different if aware of what the entire system necessitates. There is also the possibility that certain technologies are associated with others, such as CCS is often associated as coal technology with potential negative implications on the public acceptance.

Regardless of the limitations of analysing public acceptance of energy technologies, a potential reasoning from public image to energy technology market deployment is possible construct. The potential public acceptance, or rejection, can be seen to link to the relevant decision-making, and further to legal and regulatory framework, which have linkages to the availability of subsidies and funding. These factors together with techno-economic considerations, and local attitudes that affect individual projects, have an influence of the market deployment of individual energy technologies.

The limitations of this study include the used keywords potentially limiting the obtained media sentiment. Also, only English language is used. Hence, the results might be slightly different if using alternative keywords or other languages. However, the main idea is the comparison of large dataset to offset the effect of classification failures made in case of single media hit, and to indicate the comparability. This study does not attempt to explain the entire chain from public acceptability to the actual effects to managerial decision-making and technology deployment, but to describe a potential reasoning from public image to energy technology market deployment. The learning-machine based analysis has its limitations in being able to cope with a more wide-ranging flow of knowledge, the way that would be possible by interviews. However, there might be benefits in terms of dealing with value laden and subjective issues as the answers are not confined to responses and categories anticipated by the researcher, but a compilation of automated and qualitative methods. Furthermore, no content analysis was carried out due to a large dataset, nor was any framing or other discourse analysis methods used. It is also important to note that this study does not reveal the factors behind media sentiment differences locally. Local technology deployment and project planning might benefit of the local media sentiment. Neither does this study acknowledge possible factors behind regional differences, ones that may affect power deployment. Aside addressing the limitations, a potential topic for future studies could involve taking a stakeholder salience model (Mitchell et al., 1997) perspective to consider the salience of different media, or social media, and to analyse the differences in terms of potential influence on energy technology stakeholders. 


\section{References}

Abrahams, A. S., Jiao, J., Fan, W., Wang, G. A., \& Zhang, Z. (2013). What's buzzing in the blizzard of buzz? automotive component isolation in social media postings. Decision Support Systems, $55(4), 871$.

Aitken, M., 2010. Why we still don't understand the social aspects of wind power: A critique of key assumptions within the literature. Energy Policy 38(4), 1834-1841.

Ashworth, P., Boughen, N., Mayhew, M., Millar, F., 2009. An integrated roadmap of communication activities around carbon capture and storage in Australia and beyond. Energy Procedia 1(1), 4749-4756.

Barry, J., Ellis, G., \& Robinson, C. (2008). Cool rationalities and hot air: A rhetorical approach to understanding debates on renewable energy. Global Environmental Politics, 8(2), 67-98.

Batel, S., Devine-Wright, P., \& Tangeland, T. (2013). Social acceptance of low carbon energy and associated infrastructures: A critical discussion. Energy Policy, 58, 1-5.

Bradbury, J., Ray, I., Peterson, T., Wade, S., Wong-Parodi, G., Feldpausch, A. (2009) "The role of social factors in shaping public perceptions of CCS: Results of multi-state focus group interviews in the U.S.", Energy Procedia, Vol. 1, No.1, pp.4665-4672

Bello-Orgaz, G., Jung, J. J., \& Camacho, D. (2016). Social big data: Recent achievements and new challenges. Information Fusion, 28, 45-59.

Brouwer, A.S., van den Broek, M., Seebregts, A., Faaij, A., 2015. Operational flexibility and economics of power plants in future low-carbon power systems. Applied Energy 156, 107-128.

de Coninck, H., Stephens, J.C. , Metz, B., 2009. Global learning on carbon capture and storage: A call for strong international cooperation on CCS demonstration. Energy Policy 37(6), 2161-2165.

Devine-Wright, P. (2007). Reconsidering public attitudes and public acceptance of renewable energy technologies: A critical review. Manchester: School of Environment and Development, University of Manchester, UK.

Devine-Wright, P. (2011). Renewable Energy and the Public From NIMBY to Participation. Earthscan, Routledge, Oxon, UK. ISBN: 978-1-84407-863-9.

Dütschke, E. (2011) "What drives local public acceptance - comparing two cases from Germany", Energy Procedia, Vol. 4, pp.6234-6240.

Eagly, Alice H. and Shelly Chaiken (1993), The Psychology of Attitudes, New York: Harcourt Brace College Publishers.

Eiser, J. R., Hannover, B., Mann, L., Morin, M., van Der Pligt, J., \& Webley, P. (1990). Nuclear attitudes after chernobyl: A cross-national study. Journal of Environmental Psychology, 10(2), 101110. 
Ek, K. (2005). Public and private attitudes towards "green" electricity: The case of Swedish wind power. Energy Policy, 33(13), 1677-1689.

Firestone, J., Kempton, W. (2007) "Public opinion about large offshore wind power: Underlying factors", Energy Policy, Vol. 35, No. 3, pp.1584-1598.

Firestone, J., Kempton, W., Lilley, M. B., \& Samoteskul, K. (2012). Public acceptance of offshore wind power across regions and through time. Journal of Environmental Planning and Management, 55(10), 1369-1386.

Fleishman, L. A., De Bruin, W. B., \& Morgan, M. G. (2010). Informed public preferences for electricity portfolios with CCS and other Low-Carbon technologies. Risk Analysis, 30(9), 13991410.

Giner-Sorolla, Roger (1999), "Affect in Attitude: Immediate and Deliberative Perspectives," in Dual-Process Theories in Social Psychology.

Godbole, N., Srinivasaiah, M., \& Skiena, S. (2007). Large-scale sentiment analysis for news and blogs. Icwsm, 7(21), 219-222.

Greenberg, M., \& Truelove, H. B. (2011). Energy choices and risk beliefs: Is it just global warming and fear of a nuclear power plant accident? Risk Analysis, 31(5), 819-831.

De Groot, J. I., \& Steg, L. (2010). Morality and nuclear energy: Perceptions of risks and benefits, personal norms, and willingness to take action related to nuclear energy. Risk Analysis, 30(9), 1363-1373

Grove-White, R., Kearnes, M., Macnaghten, P., Wynne, B. (2006) "Nuclear futures: Assessing public attitudes to new nuclear power", Political Quarterly, Vol. 77, No. 2, pp.238-246.

Gupta, N., Fischer, A. R. H., \& Frewer, L. J. (2012). Socio-psychological determinants of public acceptance of technologies: A review. Public Understanding of Science, 21(7), 782-795.

Halder, P., Havu-Nuutinen, S., Pietarinen, J. and Pelkonen, P. (2011) 'Bio-energy and youth: analyzing the role of school, home, and media from the future policy perspectives', Applied Energy, Vol. 88, No. 4, pp.1233-1240.

Hall, N., Ashworth, P., \& Devine-Wright, P. (2013). Societal acceptance of wind farms: Analysis of four common themes across australian case studies. Energy Policy, 58, 200-208.

Heras-Saizarbitoria, I., Cilleruelo, E., \& Zamanillo, I. (2011). Public acceptance of renewables and the media: An analysis of the spanish PV solar experience. Renewable and Sustainable Energy Reviews, 15(9), 4685-4696.

Huijts, N.M.A., Midden, C.K.H., Meijnders, A.L. (2007) "Social acceptance of carbon dioxide storage", Energy Policy, Vol.35, No. 5, pp.2780-2789. 
Huijts, N.M.A., Molin,E.J.E., Steg, L. 2012. Psychological factors influencing sustainable energy technology acceptance: A review-based comprehensive framework. Renewable and Sustainable Energy Reviews 16(1), 525-531.

Itaoka, K., Saito, A., Akai, M. (2004) "Public acceptance of CO2-capture and storage technology: a survey of public opinion to explore influential factors", the Seventh International Conference on Greenhouse Gas Technologies, Vancouver, September 5, 2004.

Kaldellis, J. (2005). Social attitude towards wind energy applications in greece. Energy Policy, 33(5), 595-602.

Karvonen, E., Elämää mielikuvayhteiskunnassa. Imago ja maine menestystekijöinä myöhäismodernissa maailmassa. Gaudeamus Oy, yliopistokustannus. 334s.

Kim, Y., Kim, M., Kim, W. (2013) "Effect of the Fukushima nuclear disaster on global public acceptance of nuclear energy", Energy Policy, Vol. 61, pp.822-828.

Kumar A J., Abirami S., Trueman T.E., Sentiment Mining Approaches for Big Data Classification and Clustering. 2017. In a book Seetha, Hari, Murty, M. Narasimha, Tripathy, B. K..; Modern Technologies for Big Data Classification and Clustering . EBSCO Publishing: eBook Collection (EBSCOhost) - printed on 9/11/2017 4:39 AM

Ladenburg, J. (2008). Attitudes towards on-land and offshore wind power development in denmark; choice of development strategy. Renewable Energy, 33(1), 111-118.

Liu, B., \& Zhang, L. (2012). A survey of opinion mining and sentiment analysis. Mining text data (pp. 415-463) Springer.

Lund, P.D. (2007) "Effectiveness of policy measures in transforming the energy system", Energy Policy, Vol. 35, No. 1, pp.627-639.

M-Brain. Corporate communications. Received 11/2015.

Mathews, J.A., Kidney, S., Mallon, K., Hughes, M. (2010) "Mobilizing private finance to drive an energy industrial revolution", Energy Policy, Vol.38, No.7, pp.3263-3265.

McCorkindale, T., DiStaso, M. W., \& Carroll, C. (2013). The power of social media and its influence on corporate reputation. The Handbook of Communication and Corporate Reputation, 497-512.

McGuire, C.J. (2015) 'The role of risk perception in building sustainable policy instruments: a case study of public coastal flood insurance in the USA', Interdisciplinary Environmental Review, Vol. 16, Nos. 2-4, pp.232-252.

Midttun, A, Gautesen, K. (2007) "Feed in or certificates, competition or complementarity? Combining a static efficiency and a dynamic innovation perspective on the greening of the energy industry", Energy Policy, Vol.35, No.3, pp.1419-1422. 
Mitchell, Andrew A. and Jerry C. Olson (1981), "Are Product Beliefs the Only Mediator of Advertising Effect on Brand Attitude?” Journal of Marketing Research, 18 (August), 318-32.

Khadjeh Nassirtoussi, A., Aghabozorgi, S., Ying Wah, T., \& Ngo, D. C. L. (2014). Text mining for market prediction: A systematic review. Expert Systems with Applications, 41(16), 7653-7670.

Neviarouskaya, A., Aono, M., Predinger, H., Ishizuka, M. 2014. Intelligent Interface for textial Attitude Analysis. ACM Transactions, 5(3), Article 48.

Noelle-Neumann, Elisabeth (1986[1973]). The Spiral of Silence. Public Opinion -Our Social Skin. Chicago: University of Chicago Press.

Palmgren, C.R., Morgan, M.G., de Bruin, W.B., Keith, D.W. (2004) "Initial Public Perceptions of Deep Geological and Oceanic Disposal of Carbon Dioxide", Environmental Science \& Technology, Vol. 38, No. 24, pp.6441-6450.

Peñalver-Martinez, I., Garcia-Sanchez, F., Valencia-Garcia, R., Rodríguez-García, M. Á., Moreno, V., Fraga, A., \& Sánchez-Cervantes, J. L. (2014). Feature-based opinion mining through ontologies. Expert Systems with Applications, 41(13), 5995-6008. doi:10.1016/j.eswa.2014.03.022

Pidgeon, N. F., Lorenzoni, I., \& Poortinga, W. (2008). Climate change or nuclear power-No thanks! A quantitative study of public perceptions and risk framing in britain. Global Environmental Change, 18(1), 69-85.

Qu, M., Ahponen, P., Tahvanainen, L., Gritten, D., Mola-Yudego, B. and Pelkonen, P. (2011) 'Chinese university students' knowledge and attitudes regarding forest bio-energy', Renewable and Sustainable Energy Reviews, Vol. 15, No. 8, pp.3649-3657.

Siegrist M. (2000) "The influence of trust and perceptions of risks and benefits on the acceptance of gene technology", Risk Analysis, Vol. 20, No. 2, pp.195-203.

Siegrist, M., Cousin, M.-E., Kastenholz, H., Wiek, A. (2007a) "Public acceptance of nanotechnology foods and food packaging: The influence of affect and trust", Appetite, Vol.49, No. 2, pp.459-466.

Siegrist, M., Keller, C., Kastenholz, H., Frey, S., Wiek, A. (2007b) "Laypeople's and Experts' Perception of Nanotechnology Hazards", Risk Analysis, Vol. 27, No. 1, pp.59-69.

Siegrist, M., \& Visschers, V. H. (2013). Acceptance of nuclear power: The fukushima effect. Energy Policy, 59, 112-119.

Slotegraaf, R.J., Moorman, C., Inman, J.J. (2003) "The Role of Firm Resources in Returns to Market Deployment", Journal of Marketing Research, Vol. 40, No. 3, pp.295-309.

Slovic, P., Flynn, J., Layman, M. (1991) "Perceived Risk, Trust, and the Politics of Nuclear Waste", Science, Vol. 254, pp.1603-1608.

Sovacool, B., Ratan, P.L., 2012. Conceptualizing the acceptance of wind and solar electricity. Renewable and Sustainable Energy Reviews 16 (7), 5268-5279. 
Spears, N., \& Singh, S. N. (2004). Measuring attitude toward the brand and purchase intentions. Journal of Current Issues \& Research in Advertising, 26(2), 53-66

Tanaka, Y. (2004). Major psychological factors determining public acceptance of the siting of nuclear facilities. Journal of Applied Social Psychology, 34(6), 1147-1165

Terwel, B.W., Harinck, F., Ellemers, N., Daamen, D.D.L. (2009) "Competence-Based and Integrity-Based Trust as Predictors of Acceptance of Carbon Dioxide Capture and Storage (CCS)", Risk Analysis, Vol. 29, No. 8, pp.1129-1140.

Terwel, B.W., Harinck, F., Ellemers, N., Daamen, D.D.L. (2011) "Going beyond the properties of $\mathrm{CO} 2$ capture and storage (CCS) technology: How trust in stakeholders affects public acceptance of CCS", International Journal of Greenhouse Gas Control, Vol. 5, No. 2, pp.181-188.'

Teräväinen, T., Lehtonen, M., \& Martiskainen, M. (2011). Climate change, energy security, and risk - debating nuclear new build in finland, france and the UK. Energy Policy, 39(6), 3434-3442.

Wallquist, L., Visschers, V.H.M., Siegrist, M. (2010) "Impact of Knowledge and Misconceptions on Benefit and Risk Perception of CCS", Environmental Science \& Technology, Vol. 44, No. 17, pp.6557-6562.

Warren, C. R., \& Birnie, R. V. (2009). Re-powering scotland: Wind farms and the 'energy or environment?'Debate. Scottish Geographical Journal, 125(2), 97-126

Verplanken, B. (1989). Beliefs, attitudes, and intentions toward nuclear energy before and after chernobyl in a longitudinal within-subjects design. Environment and Behavior, 21(4), 371-392.

Wolsink, M. 2000. Wind power and the NIMBY-myth: Institutional capacity and the limited significance of public support. Renewable Energy, 21(1), 49-64.

Wolsink, M. (2007) "Wind power implementation: The nature of public attitudes: Equity and fairness instead of 'backyard motives', Renewable and Sustainable Energy Reviews, Vol. 11, No. 6, pp. 1188-1207.

Wüstenhagen, R., Wolsink, M., Bürera, M.J. (2007) "Social acceptance of renewable energy innovation: An introduction to the concept", Energy Policy, Vol. 35, No. 5, pp.2683-2691.

Ye, Q., Li, H., Wang, Z., \& Law, R. (2014). The influence of hotel price on perceived service quality and value in e-tourism: An empirical investigation based on online traveler reviews. Journal of Hospitality \& Tourism Research, 38(1), 23-39.

Zechendorf, B. (1994) "What the Public Thinks about Biotechnology," Bio/Technology, Vol. 12, pp.870-875.

Zhang, C., Zuo, W., Peng, T., \& He, F. (2008). Sentiment classification for chinese reviews using machine learning methods based on string kernel.Convergence and Hybrid Information Technology, 2008. ICCIT'08. Third International Conference on, , 2. pp. 909-914 
Zoellner, J., Schweizer-Ries, P., \& Wemheuer, C. (2008). Public acceptance of renewable energies:

Results from case studies in germany. Energy Policy, 36(11), 4136-4141. 